\title{
Applications of the Chick Chorioallantoic Membrane as an Alternative Model for Cancer Studies
}

\author{
Pei-Yu Chu ${ }^{a}$ Angele Pei-Fern Koh ${ }^{b}$ Jane Antony ${ }^{c}$ Ruby Yun-Ju Huang d, e \\ ${ }^{a}$ Graduate Institute of Pharmacology, College of Medicine, National Taiwan University, Taipei, Taiwan; \\ ${ }^{b}$ Cancer Science Institute of Singapore, Center for Translational Medicine, National University of Singapore, \\ Singapore, Singapore; 'Institute for Stem Cell Biology and Regenerative Medicine, Stanford, CA, USA; ${ }^{\text {SSchool of }}$ \\ Medicine and Graduate Institute of Oncology, College of Medicine, National Taiwan University, Taipei, Taiwan; \\ eDepartment of Obstetrics and Gynaecology, Yong Loo Lin School of Medicine, National University of Singapore, \\ Singapore, Singapore
}

\author{
Keywords \\ Chorioallantoic membrane $\cdot$ Tumor $\cdot$ Cancer $\cdot$ Patient- \\ derived xenograft
}

\begin{abstract}
A variety of in vivo experimental models have been established for the studies of human cancer using both cancer cell lines and patient-derived xenografts (PDXs). In order to meet the aspiration of precision medicine, the in vivomurine models have been widely adopted. However, common constraints such as high cost, long duration of experiments, and low engraftment efficiency remained to be resolved. The chick embryo chorioallantoic membrane (CAM) is an alternative model to overcome some of these limitations. Here, we provide an overview of the applications of the chick CAM model in the study of oncology. The CAM model has shown significant retention of tumor heterogeneity alongside increased xenograft take rates in several PDX studies. Various imaging techniques and data analysis have been applied to study tumor metastasis, angiogenesis, and therapeutic response to novel agents. Lastly, to practically illustrate the
\end{abstract}

karger@karger.com www.karger.com/cto

Karger $\stackrel{\text { ' }}{5}$

GOPEN ACCESS
(C) 2021 The Author(s)

Published by S. Karger AG, Basel

This is an Open Access article licensed under the Creative Commons Attribution-NonCommercial-4.0 International License (CC BY-NC) (http://www.karger.com/Services/OpenAccessLicense), applicable to the online version of the article only. Usage and distribution for commercial purposes requires written permission. feasibility of utilizing the CAM model, we summarize the general protocol used in a case study utilizing an ovarian cancer PDX.

(c) 2021 The Author(s)

Published by S. Karger AG, Basel

\section{Introduction}

As the pursuance of precision medicine in oncology is based on the scientific evidences of different pathogenesis pathways and genomic variations between patients, researchers have been seeking suitable and effective experimental platforms to reflect these complexities. Patientderived models have been regarded to be such to test out individualized treatment. Existing patient-derived experimental models for oncology studies include in vitro 2D cell culture, 3D tumor organoids, and in vivoxenograft models in rodents, zebrafish and avian. Among the in vivo models, the patient-derived xenograft (PDX) models in immunodeficient mice are the most used. Mice with different immunodeficiency profiles are derived from well-defined genetic backgrounds which create homoge- 
neous experimental settings. PDX grafted in these mice could be observed for a longer period following the growth of the mice. The murine PDX model enables transplantation of a larger range of orthotopic tissues which are suitable for primary tumor expansion from biopsies [Veinotte et al., 2014]. However, while the murine PDX models carry several benefits, critical limitations also exist. The cost to maintain the colony in the animal facility could be high and the access to these models might not be widely available in some low-resourced regions. The extended lag-time to establish the xenograft take could range from 2 to 8 months [Jung et al., 2018]. In addition, the successful take rate of PDX could also be affected by different immunodeficiency backgrounds of the mouse strains [Xu et al., 2019]. Therefore, despite the wide application of the murine PDX model, alternatives are still needed to bridge these shortcomings.

\section{Using Chick Chorioallantoic Membrane Model for Human Cancer Studies}

The chick chorioallantoic membrane (CAM) model has emerged to be a good experimental system to establish a patient-derived model. It provides a unique biological microenvironment appropriate for cancer cells. The CAM is a structure fusing the mesoderm layer of allantois and chorion membranes with a rich vascular network [Ribatti, 2016]. The rich vascular plexus within the mesoderm layer of CAM supported by allantoic arteries and veins, offers tumor cells a supplement of growth-essential nutrients. The secretion of tumor angiogenic factors enables penetration of proliferating host vessels which bring oxygen to the graft [Folkman, 1971]. The time-course and onset of vascularization inside the CAM tumor graft has been clearly demonstrated [Knighton et al., 1977]. There is an initial avascular phase during the first $72 \mathrm{~h}$ of grafting [Knighton et al., 1977], during which the tumor growth is highly restricted [Ausprunk et al., 1975; Ausprunk and Folkman, 1976; Knighton et al., 1977]. In the meantime, the endothelial cells also undergo dynamic changes during the avascular phase. Due to ischemic damages, the endothelial cells in tumor grafts disintegrate and undergo lipid accumulation, vacuolation and degeneration at $2 \mathrm{~h}, 8 \mathrm{~h}$, and 2 days post-implantation, respectively [Ausprunk et al., 1975; Ausprunk and Folkman, 1976]. The avascular tumor grafts on CAM eventually undergo necrosis and autolysis during the pre-vascular phase [Ribatti, 2008]. The neovascularization begins approximately $72-96 \mathrm{~h}$ after implantation, which is fol- lowed by a rapid growing phase [Knighton et al., 1977]. The reperfusion of vessels occurs through the release of angiogenic factors by tumor cells at the later phase and rescues the necrosis of tumor cells subsequently. The existence of this microvasculature inside the CAM system plays a crucial role in tumor cell proliferation and survival for the CAM xenograft.

The chick embryo development lasts for 21 days after which it hatches. The innate immune system starts developing during early embryo incubation starting from embryonic day (ED) 3 till ED16 when it is well-developed. The adaptive immunity develops later from around ED10 to ED18, which is when chick embryos are immunocompetent to react to pathogens via both innate and adaptive immune systems [Hincke et al., 2019]. Therefore, the developing chick embryo is naturally in an immunodeficient state until ED18 making the CAM an ideal setting for tumor grafting. From ED3 onwards, the chick embryo starts to express toll-like receptors, which prepare the embryo to defend pathogens through its innate immunity [Meade et al., 2009; Kannaki et al., 2015]. Macrophages can be observed inside the chick circulation from ED4 and could be detected in liver after ED12. The liver and spleen residing macrophages are functional as early as ED12 and ED16 [Janse and Jeurissen, 1991; Qureshi et al., 2000]. These embryonic macrophages have been shown to not only phagocytose dead cells [Cuadros et al., 1992], but also to guide the development of the lymphoid system [Houssaint, 1987; Houssaint et al., 1987]. Another inflammatory cell type existing during the early chick embryo incubation period are heterophils, which are analogs of the mammalian neutrophils contributing to the production of matrix metalloproteinase-9 (MMP-9) [Zijlstra et al., 2006]. Similar to mammalians, the chick adaptive immune system consists the T cells and B cells. T cells are first released from the thymus on around ED6. The second wave of release happens around ED11, which is when they develop functionally [Jankovic et al., 1975; Davison, 2003; Schilling et al., 2018; Hincke et al., 2019]. On the other hand, pre-bursal B cell precursors originating from the bursa of Fabricius are released on ED8 [Ratcliffe and Härtl, 2014], fully developed by ED12, and are differentiated after ED15 [Davison, 2003; Schilling et al., 2018; Hincke et al., 2019]. Therefore, the chick embryo becomes fully immunocompetent in both the innate and adaptive immune system only after ED18. This immature immune system before ED18 allows a higher rate of successfully accepting tumor transplantation, either allograft or xenograft [Davison, 2003; Schilling et al., 2018; Hincke et al., 2019]. Moreover, this immature immune environ- 
Table 1. General advantages/disadvantages of the CAM assay

\begin{tabular}{|c|c|c|}
\hline & Advantages & Disadvantages \\
\hline \multirow[t]{5}{*}{ Technical } & Short experimental duration & Short observation period \\
\hline & Inexpensive & \\
\hline & $\begin{array}{l}\text { Allows multiple tests per individual CAM [Bertossi et al., 1999; } \\
\text { Deryugina, 2016] }\end{array}$ & \\
\hline & High reproducibility & \\
\hline & Allows continuous/direct visualization & \\
\hline \multirow[t]{5}{*}{ Biological } & Naturally immunodeficient & Unable to examine tumor-immune cell interaction \\
\hline & & $\begin{array}{l}\text { Non-specific inflammatory reaction after chick } \\
\text { immune system development }\end{array}$ \\
\hline & Highly vascularized environment for tumor growth & $\begin{array}{l}\text { Difficult in distinguishing neovascularization and } \\
\text { existing vessels }\end{array}$ \\
\hline & Closed system & $\begin{array}{l}\text { Sensitive to environmental factors (e.g., changes in } \\
\text { pH, osmolarity and oxygen level) }\end{array}$ \\
\hline & High feasibility on primary human cell lines & $\begin{array}{l}\text { Limited antibodies and cytokines for chicken tissue } \\
\text { characterization }\end{array}$ \\
\hline
\end{tabular}

ment has been shown to allow the preservation of immunogenic characteristics from human cells. The expression of human antigens has been shown to be retained after transplantation and re-transplantation of human tumors on CAM for several passages [Korngold and Lipari, 1955]. This suggests that the immunogenic property to recruit immune cells to the human tumor grafts would still be preserved. This further gives strong indications that the related functionality and biological behaviors of the tumor grafts could also be retained, which is an important consideration for the application of PDXs.

The CAM model could overcome limitations encountered in the murine models to establish PDXs (Table 1). The cost-effectiveness, simplicity, high reproducibility, visibility, and shorter experimental duration make the
CAM model a suitable alternative [Tufan and SatirogluTufan, 2005]. The lower cost of the embryonic eggs, the elimination of forage and reduced facility access costs makes the CAM model more cost-effective compared to the immunodeficient mice. The manipulation to the eggs is simpler than handling the mice. The access to the CAM simply requires an opening of a window on the eggshell. The lower cost and the simplicity of CAM makes scaling up the experiments in multiple repeats feasible. Therefore, the chick CAM model could deliver experimental data with higher reproducibility. As the CAM is positioned right underneath the eggshell and on top of the developing embryo, no further surgery is required to examine the CAM tumor grafts. This allows the application of several imaging methods which could greatly enhance 
Table 2. Cancer cell lines/human tumor tissues applied to the CAM assay

\begin{tabular}{|c|c|c|c|}
\hline Type of Tumor/cell lines & References & Type of Tumor/Cell lines & References \\
\hline Breast carcinoma & Ames et al., 2016; Zuo et al., 2017 & Melanoma & Kaufman et al., 1956; Lugassy et al., 2009 \\
\hline Fibrosarcoma & $\begin{array}{l}\text { Deryugina and Quigley, } 2008 \text {; Zabielska- } \\
\text { Koczywas et al., } 2017\end{array}$ & $\begin{array}{l}\text { Nasopharyngeal carcinoma } \\
\text { (head and neck cancer) }\end{array}$ & $\begin{array}{l}\text { Petruzzelli et al., 1993; Oh et al., 2012; Xiao et } \\
\text { al., 2015; Rudy et al., } 2016\end{array}$ \\
\hline Glioblastoma & $\begin{array}{l}\text { Balciuniene et al., 2009; Strojnik et al., } \\
2010\end{array}$ & Osteosarcoma & Jefferies et al., 2017; Walewska et al., 2017 \\
\hline Glioma & $\begin{array}{l}\text { Kaufman et al., 1956; Mostafa et al., 1980; } \\
\text { Shoin et al., } 1991\end{array}$ & Ovarian carcinoma & $\begin{array}{l}\text { Ismail et al., 1999; Lokman et al., 2012; Vu et al., } \\
2018\end{array}$ \\
\hline Lung cancer & $\begin{array}{l}\text { Kaufman et al., 1956; Huang WT et al., } \\
\text { 2017; Swadi et al., } 2018\end{array}$ & Renal carcinoma & Fergelot et al., 2013; Ferician et al., 2015 \\
\hline Lymphoma cell & $\begin{array}{l}\text { Mostafa et al., 1980; Klingenberg et al., } \\
2014\end{array}$ & Urothelial carcinoma & Skowron et al., 2017 \\
\hline Medullary thyroid cancer & Ghaffari-Tabrizi-Wizsy et al., 2019 & & \\
\hline
\end{tabular}

the visualization. As the experiments are always synchronized with the embryonic development of the chick before hatching, the duration to establish the graft only requires 14-18 days which is significantly shorter than what is usually needed for the mouse model. These advantages, together with the ability to inoculate multiple samples of interest onto individual CAMs [Bertossi et al., 1999; Deryugina, 2016], position the CAM as a good model to set up a large scale in vivodrug screening platform. It has been reported that experimental compounds have a longer half-life in the enclosed CAM system compared to other animal models [Lokman et al., 2012]. This unique feature could make drug testing in the CAM system more stable in pharmacodynamics and pharmacokinetics.

\section{Applications of the CAM Model in Human Cancer Studies}

Functional assessments of tumor growth, angiogenesis, and metastasis have been studied by using the CAM platform [Shioda et al., 1997; Cimpean et al., 2008; Deryugina and Quigley, 2008]. Both immortalized cancer cell lines (CCLs) and patient-derived samples have been successfully inoculated onto the surface of CAM [Karnofsky et al., 1952; Dagg et al., 1956; Gronau et al., 2006; Lugassy et al., 2009; Klingenberg et al., 2014; Xiao et al., 2015; Zabielska-Koczywas et al., 2017] or been injected into the veins of CAM [Ho et al., 2010; Leong et al., 2012]. Various types of CCLs or patient-derived tumors have been tested in the CAM model (Table 2).

\section{Retainment of the Tumor Heterogeneity in the CAM Model}

It is known that tumor harbors extensive heterogeneity [Dagogo-Jack and Shaw, 2018] which is reflected in multiple cancer hallmarks [Hanahan and Weinberg, 2011]. Any experimental model aiming to fulfill the goal of achieving precision medicine should at least in part reflect the underlying tumor heterogeneity. Therefore, the retainment of the heterogeneity becomes crucial in any pre-clinical model. With regards to the CAM model, both CCLs and PDXs have been shown to exhibit pros and cons in retaining tumor heterogeneity.

Several observations have been made that tumors formed in the CAM from CCLs could recapitulate the 
original features to some degree. In melanoma, tumors formed by the inoculation of cell lines onto the CAM displayed similar morphologies to the patient tumors [Durupt et al., 2012]. The resemblance to the tumor microenvironment composition, consisting of cancer cells, extracellular matrix, collagen, stromal cells, and tumor vasculature, was also reported [Vu et al., 2018; Komatsu et al., 2019] in the CAM tumors formed by the ovarian and lung CCLs. However, these tumors derived from CCLs still suffer from the known drawbacks of in vitro culturing of CCLs prior to the grafting onto the CAM. Loss of biological complexity under the culture conditions and the acquisition of additional molecular alternations during the culture adaption process would eventually render the CAM tumor graft to acquire heterogeneity not observed in the actual patient tumors. Firstly, the growing environment of CCLs in the culture medium is too simple compared to in vivo samples, and this might not be representative of the tumor microenvironment. Also, different culture microenvironments would predominantly select certain subpopulations from immortalized CCLs. Secondly, new mutations might occur during cell culture adaptation and can alter the cellular composition and morphology [Fiebig et al., 2004], which might lead to varied experimental results between passages. Cells might possess inherent demerits after passages with unexpected genetic instabilities [Masters, 2000; Sachs and Clevers, 2014]. Nevertheless, due to its wide availability, immortalized CCLs grown on the CAM are still very useful in the study of molecular mechanisms and preclinical tests or screening for drugs [Steiner, 1992; Durupt et al., 2012; Rovithi et al., 2017; Vu et al., 2018].

PDXs in CAM have been shown to maintain the heterogeneity, pathophysiology, and major morphological and cellular features of the original tumors with high fidelity [DeBord et al., 2018]. In a study of grafting pancreatic ductal adenocarcinoma (PDAC) tumors onto the CAM [Rovithi et al., 2017], the retainment of morphological and cellular heterogeneity were demonstrated by immunohistochemistry (IHC) staining of several PDAC markers such as cytokeratin 7 (CK7), CK19 and mucin-1 (MUC1). More importantly, the genetic features including common mutations such as KRAS, TP53, CDKN2A/p16INK4a, and SMAD4/DPC4 in PDAC were also preserved. Other molecular features including proliferation markers such as Ki67 have also been shown to be retained in a study of recurrent respiratory papilloma [Uloza et al., 2017]. The retention of morphological and cellular heterogeneity of the parental tumors indicates that the tumors do not lose their essential characteristics upon grafting. Furthermore, cancer-related viral genome information such as the Epstein-Barr virus in nasopharyngeal carcinoma was shown to retain in the grafted patient biopsies [Xiao et al., 2015], suggesting that pathophysiological features could also be kept in the CAMPDXs. In addition, the retention of surrounding tumor microenvironment including the tumor vasculature, stroma [Fergelot et al., 2013] and immuno-infiltration [Balciuniene et al., 2009] have also been reported. However, although CAM-PDXs have been shown to preserve the histological and morphological characteristics, some features have been reported to be divergent from parent tumors. In a series of 28 patients with tumor tissues of the musculoskeletal system, Sys et al. [2012] demonstrated that, despite the retainment of essential features such as immunohistochemical characteristics of the original tumors, the human tumor-associated stroma was largely replaced by chicken-derived stroma in the CAM-PDXs, which was similar to what has been observed in the murine PDX model. In general, the ability to retain the majority of the tumor features makes CAM a reliable system to model tumor heterogeneity.

\section{Enhancing the Xenograft Take Rate across Different}

Tumor Types in the CAM Model

The enhanced tumor take rate in the CAM model is one of the most significant advantages over the rodent model [Ribatti, 2014]. Low engraftment rates in immunodeficient mice have been observed in several specific types of tumor [Tentler et al., 2012]. For instance, DeRose et al. [2011] showed merely $24 \%$ take rate of breast tumor grafts using the NOD/SCID mouse model; Zätterström et al. [1992] demonstrated a $29 \%$ take rate of head and neck cancer tumor grafts using either B10.LP/Cpb or BALB/C nude mice. Although the use of the NSG immunodeficient mice has greatly improved the take rate, the relatively high cost to maintain these colonies in the animal facility might not be sustainable for low-resource settings. In an early study, 28 out of 59 (47\%) human cancers were shown to achieve successful transplantations in the CAM system, although with varied transplantation efficiency [Sommers et al., 1952]. There has been significant improvement of the grafting take rate using the CAM assay over the decades, which has reached to almost $100 \%$ in cases such as glioma [Shoin et al., 1991] and renal clear cell carcinoma [Fergelot et al., 2013]. Due to its high take rate, the potential of the CAM assay for PDX has gained wide acceptance in different tumor types. A detailed summary showing the steadily increased take rate over the past century has been reviewed [DeBord et al., 2018]. Sev- 
eral factors would determine the take rates in the CAM model. The take rates of grafts and the chick embryo survival would increase if less invasive inoculation techniques are utilized [Sommers et al., 1952]. Cells of distinct intrinsic properties have been shown to display different take rates [Sommers et al., 1952; Kaufman et al., 1956]. Tumors such as glioblastoma, sarcoma, nasopharyngeal carcinoma, and renal cell carcinoma have been reported to produce higher take rates from 80 to $100 \%$ [DeBord et al., 2018]. However, certain tumor types such as giant cell tumors and head and neck squamous cell carcinoma could only reach take rates around approximately $50 \%$ [DeBord et al., 2018]. Nevertheless, the overall take rates of tumors in the CAM model are still better than the murine models.

\section{Metastasis in the CAM Model}

Both spontaneous and experimental models can be established to study tumor metastasis in CAM. The spontaneous model is to examine metastasis after grafting tumor cells or patient-derived samples on the surface of CAM. The experimental model is to study metastasis by inoculating tumor cells by direct injection into the allantoic vein. Since the metastasis of tumor cells includes a series of processes, these 2 different settings are to distinguish different functionalities of nonmetastatic and metastatic cells. Penetration of tumor cells through the CAM and the ability of cells to intravasate (the invasion of tumor cells into blood vessels) can be examined by the spontaneous model. Extravasation, docking and growth of tumor cells to secondary organs, is usually studied by the experimental model. Both models can be used to quantify survival and arrestment of tumor cells in the vasculature. Interestingly, cancer cells tend to arrest in the microcirculation of CAM with a high survival and extravasation rate [Chambers et al., 1982]. While in mice, circulating cancer cells perished rapidly and underwent significant cell damages with a low extravasation rate [Massagué and Obenauf, 2016]. The choice cellular arrest or dormancy and proliferation of cancer cells in the CAM system could be contributed by the urokinase plasminogen activator receptor [Landree et al., 2004] and the activation of ERK and p38 pathways [Ossowski et al., 1999; Aguirre-Ghiso et al., 2001, 2003, 2004]. Colonization at various metastatic sites could also be established by the CAM model. Dagg et al. [1956] demonstrated that squamous cell carcinoma implanted on the surface of CAM metastasized to the eye, brain, liver and myocardium of the chick embryo. The ability to model metastasis to a diverse range of embryonic chick organs makes the CAM model more desirable to study the organ-specific metastatic process. Human leukemia cells have been shown to metastasize to the chick brain, displaying a more coherent outcome in human leukemia progression, as sites of metastasis in mice are sometimes restricted [Taizi et al., 2006].

Several methods have been developed to examine tumor morphology at the metastatic sites. Classic techniques used in the murine models such as the hematoxylin and eosin (H\&E) or IHC staining of tumor sections are generally applicable for the CAM tumor grafts (Fig. 1). This allows the identification of different cell morphologies and cell types and to assess the invasion of inoculated cells into the underlying CAM tissue. Cell-labeling with fluorescent tags would further facilitate the examination of metastatic steps in the CAM model. By using fluorescence-tagged human HT-1080 fibrosarcoma cells and the concurrent labeling of vasculature with fluorescencetagged Lens culinaris agglutinin, real-time imaging has elegantly demonstrated the intravasation, dissemination as well as extravasation of cancer cells with high (HT-hi/ diss) and low (HT-lo/diss) disseminating potential [Deryugina et al., 2005; Deryugina and Quigley, 2008]. This double labeling technique allowed clear distinction between the intravasating cancer cells and the endothelial cells to assess the dynamic interaction with the microenvironment during metastasis. From this study, HT-hi/ diss cells were found to display a behavior called vasculotropism, which is the wrapping of tumor cells by blood vessels instead of being randomly distributed within the CAM mesoderm. The attraction of HT-hi/diss cells to blood vessels enables intravasation. In contrast, only few HT-lo/diss cells appeared to escape from the primary site of inoculation, and thereby maintained a relatively clear tumor-stroma border.

In addition to the evaluation of metastatic ability, quantitative studies of each step within the metastatic cascade can be done by the CAM assay [Zijlstra et al., 2002]. This could be done by tracking of mRNA levels of metastasizing cancer cells in chick embryos [Shioda et al., 1997] or detecting the human-specific Alu sequences in the metastatic sites. PCR-mediated amplification and quantification of human Alu sequences helps correlate the fraction of human tumor cells intravasating and disseminating into the chick embryo through the CAM [Kim et al., 1998; Schneider et al., 2002]. High expression of metastasis-related genes in the circulating cancer cells has suggested that the host-cancer cell interactions alter gene expressions in early phases of metastasis [Shioda et al., 1997]. 


\section{Angiogenesis in the CAM Model}

Angiogenesis is a process that new blood vessels generate from the pre-existing vasculature. Tumor cells stimulate angiogenesis from surrounding capillary blood vessels [Folkman, 1971] to supply nutrients and chemicals to aid and maintain tumor growth. The sprouting neo-vasculatures also serve as a gateway for tumor metastasis for tumor cells to enter the circulation system. As the CAM is covered with rich vasculature, it is the first in vivo platform being used to assess angiogenesis. In 1976, the potency of extracellular factors produced by tumors to affect the tumor vascularity were examined by the host-mediated vascular response of the CAM [Klagsbrun et al., 1976]. This was even before the identification of first tumor angiogenesis factor, basic fibroblast growth factor [Shing et al., 1984]. The secretion of TAFs was reported to cause an enlargement and thickening of the mesenchyme of CAM and to increase the vascularization area of the CAM upon tumor transplantation [Ribatti et al., 1996; Valdes et al., 2002; Balciuniene et al., 2009; Uloza et al., 2015]. The CAM model has thus became widely used to investigate the anti-cancer effects of anti-angiogenic agents. A wide range of agents including growth factors, hormones, gases, antibodies, small molecule drugs, antibiotics, chemical compounds, and organo-metallic compounds have been tested for their anti-angiogenesis functions by using the CAM assay [Tufan and Satiroglu-Tufan, 2005]. These agents can be applied through intermediaries such as filter papers and polymerized materials such as Matrigel [Kisker et al., 2001], methylcellulose [Rovithi et al., 2017] and gelatin sponge [Ribatti et al., 2006] or via direct intravenous injection. To accurately evaluate the anti-angiogenesis effect of the applied molecules, quantitative or qualitative assessments of the CAM vasculatures by various imaging techniques have been developed. Macroscopic examination allows a broad view of the vasculature on the CAM [Ribatti, 2014], while light microscopy and even transmission electron microscopy would enable a more elaborative observation on the vascular remodeling [Dimova et al., 2019]. Fluorescence-based microscopy is useful to observe fluorescence-tagged Lens culinaris agglutinin labeled CAM vasculature and the fluorophorelabeled cancer cells during metastasis. Quantitatively, several analytical methods have been developed to provide measurable readouts for angiogenesis. Features such as vascular density [Form and Auerbach, 1983; Barrie et al., 1993], vessel branching points [Doukas et al., 2006; Vickerman et al., 2009; Nowak-Sliwinska et al., 2010], vascular length [DeFouw et al., 1989; Dimitropoulou et al., 1998; Seidlitz et al., 2004; Pyriochou et al., 2007], vas- cular end-points (the discrete points where the arterioles and venules connect to the capillary plexus) [Strick et al., 1991], or vessel diameter [DeFouw et al., 1989; Tay et al., 2012], arborization of vessels through counting fractal dimensions [Kirchner et al., 1996] have been assessed by various scoring methods. These quantitative methods allow the objective observation of the vasculature on the CAM from digital images. However, not all quantitative methods would be able to reflect subtle changes in angiogenesis. Therefore, a mix and match of imaging techniques and analyzing methods on selected parameters with cross referencing the results analyzed by different endpoints is highly recommended

There are limitations for the CAM model for the investigation of angiogenesis in tumor. During embryo development, there are vasculature changes resulting from endothelial cell proliferation and neovascularization. As a result, it might be difficult to distinguish between the tumor-related neo-angiogenesis and the existing embryonic neovascularization to some extent. This confounding situation may affect data interpretation. To overcome this, quantification of vessels should preferentially be done in the window when the embryonic neovascularization declines. Generally, ED10/11 to ED14-15 is considered an appropriate period for this assessment, as the endothelial mitotic index of CAM decreases rapidly after ED11 [Ribatti et al., 2001a, b], and the structure of CAM on ED13-14 expands with less complexity [Schlatter et al., 1997].

\section{Case Study: Establishing Ovarian Cancer PDX in the CAM Model}

To better appreciate how the CAM model can be an alternative in establishing the PDX, we utilize an ovarian cancer case study to demonstrate the know-how and the feasibility of this platform. Ovarian cancer (OC), one of the most deadly gynecological malignancies, is characterized by diverse histopathological and molecular heterogeneity. The complexity of heterogenous ovarian tumors can be delineated into various molecular subtypes based on gene expression profiling [Tothill et al., 2008; Cancer Genome Atlas Research Network, 2011; Tan et al., 2013]. Establishing OC PDXs would provide an ideal platform to test and validate subtype-specific therapeutics to better achieve precision management. Ten different patient samples were cut and grafted onto the CAM, and 5 of the tumors grafted showed tumor cells, papillary structures, and squamous proliferations in the H\&E slides. Although 


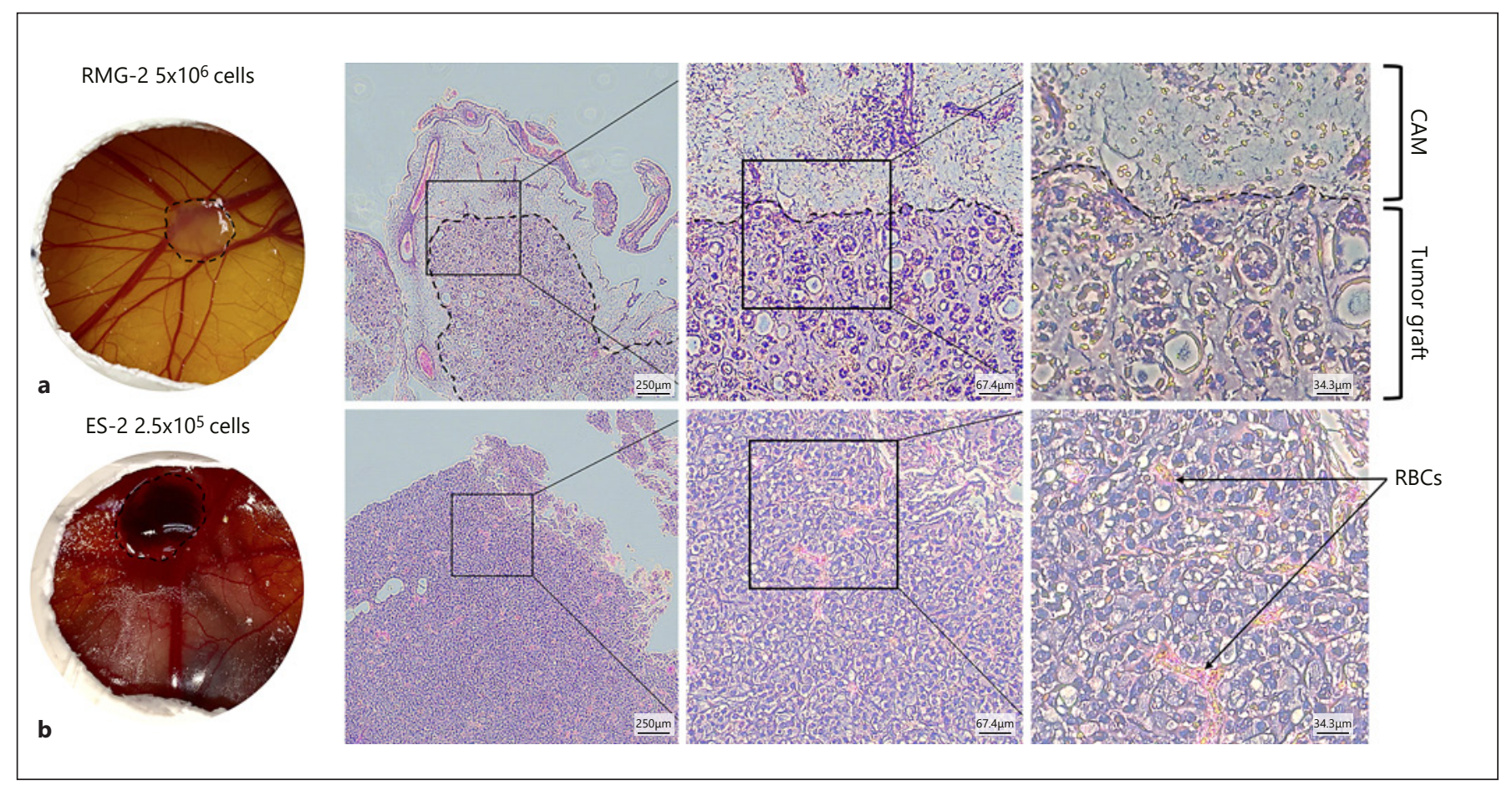

Fig. 1. Inoculation of ovarian clear cell carcinoma cell lines onto the chick CAM. On embrionic day (ED) 7, ovarian clear cell carcinoma (OCCC) cell lines a RMG2 $\left(5 \times 10^{5}\right.$ cells) or b ES2 $\left(2.5 \times 10^{5}\right.$ cells) were inoculated onto the CAM. Tumor observation and excision was done on ED14. The left panel shows the appearance of tumor grafts on the CAM. The excised tumors were sectioned and hematoxylin and eosin $(\mathrm{H} \& \mathrm{E})$ stained. The middle panel is the vi- sion of the H\&E section under an inverted light microscope at $\times 4$ magnification. Higher magnification $(\times 10)$ is shown in the middle panel square, and a much higher magnification $(\times 20)$ of the square is shown in the right panel. Dashed lines indicate the edge of the CAM and the tumor graft. Black arrows point to red blood cells (RBCs). the rate of success is only $50 \%$, this provides a promising start to grafting patient tumors onto the CAM, which retain the characteristics of the original patient tumor. Hence, we provide a case study of particular ovarian tumor grafted onto the CAM and the subsequent assays carried out thereafter to provide more insight of the utilization of the chick CAM model in the study of oncology. Here, we summarize the general protocol for establishing the OC PDX in CAM (Fig. 2) and the basic assessment of the tumor growth and the preservation of histopathological features. This shows that the CAM model is a robust assay to graft tumor fragments derived from OC patients.

\section{General Protocol for OC CAM Xenografts}

\section{Incubation of Eggs}

Freshly fertilized chick eggs are collected from a local SPF (specific pathogen free) facility are designated as ED0. Eggs are wiped with dry paper towels to remove any dirt. Cleaning with $70 \%$ ethanol or other cleaning reagent would significantly reduce the survival rate of embryos, and hence, must be avoided. Eggs are set horizontally on one side, with the upper surface marked and labeled. Incubation temperature of the Rcom Max 50 incubator is to be set at $37.5^{\circ} \mathrm{C}$ and $60 \%$ humidity. The automatic rotation option is switched off with the ventilation of the incubator is to be left half open.

\section{Preparation of the CAM}

The preparation of the chick CAM is to be conducted within a biosafety cabinet. The eggs should not be opened later than ED3 as the membrane tends to stick to the shell, resulting in the damage to the CAM. The level of the CAM is lowered by removing 3-4 $\mathrm{mL}$ of albumin using a thin needle inserted at the apex of the egg before opening the egg. A $3 \mathrm{M}^{\mathrm{TM}}$ Tegaderm ${ }^{\mathrm{TM}}$ transparent film dressing is applied to prevent the falling of shell particles onto the CAM while cutting a window in the egg. A small window of $1 \mathrm{~cm}^{2}$ is made in the shell. At ED3, the chick's pulsating 


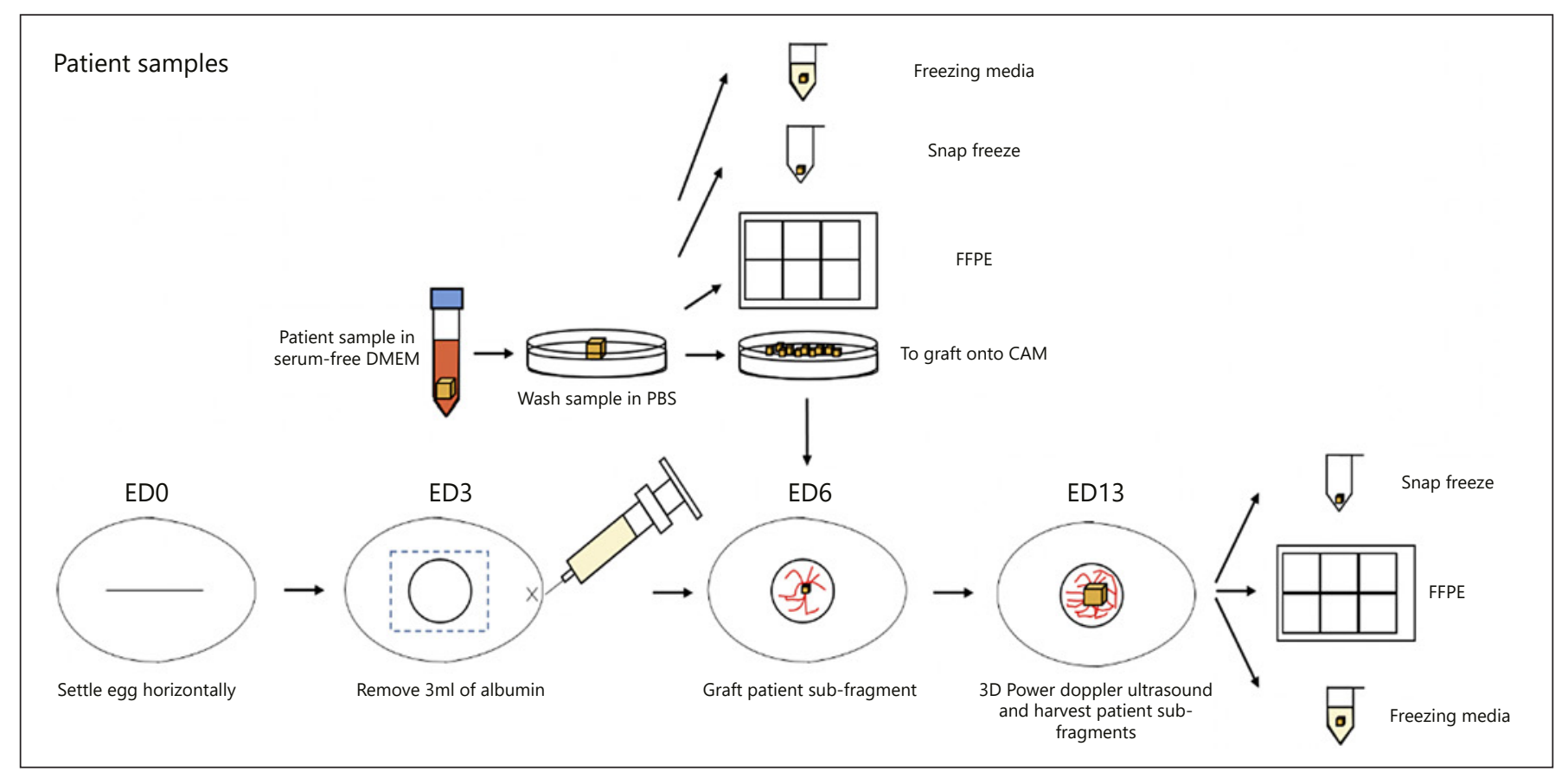

Fig. 2. Overview of CAM protocol for patient samples. Fertilized eggs were collected from a local farm and designated as embryonic day (ED) 0 . The eggs were mechanically wiped with dry paper towels and set horizontally in the Rcom Max 50 incubator at $37.5^{\circ} \mathrm{C}$ and $60 \%$ humidity. On ED3, $3 \mathrm{~mL}$ of the albumin was removed using a syringe and needle, and a small window of $1 \mathrm{~cm}^{2}$ was made in the center of the egg, and then sealed with a semipermeable adhesive film. On ED6, the patient tumor was collected in serum-free DMEM, washed in PBS, and cut into fragments of approximately $3 \times 3 \times 3 \mathrm{~mm}$ to be grafted onto the chorioallantoic membrane

heart and the supporting vessels could be observed at the surface of the egg yolk. The window is then resealed with a $3 \mathrm{M}^{\mathrm{TM}}$ Tegaderm ${ }^{\mathrm{TM}}$ transparent film dressing. The grafting of tumors onto the CAM occurs on ED6 or 7 as the chick embryos are less sensitive to agitation.

\section{Grafting of OC Tumor Fragments onto the CAM}

In the operating theater, tumor fragments from an advanced late-stage OC patient are collected (Fig. 3a) and immediately placed in serum-free DMEM in a $50 \mathrm{~mL}$ falcon tube and stored on ice until engraftment onto the CAM. The fragments are further divided into smaller subfragments (Fig. 3b) on a sterile Petri dish in the biosafety cabinet by using a sterile scalpel to cut fragments of around $3 \times 3 \times 3 \mathrm{~mm}^{3}$ from macroscopically homogenous parts of the tumor specimen that lack visible signs of necrosis. Some fragments are formalin-fixed paraffin-embedded (FFPE) for IHC or H\&E staining, some fragments are snap frozen in liquid nitrogen or dry ice for future
(CAM). The remaining fragments of the patient tumor was kept in freezing media, snap frozen and fixed in formalin before being embedded in paraffin. The percentage vascularity and volume of the grafted patient tumor was then measured using the $3 \mathrm{D}$ power Doppler ultrasound and was allowed to grow till ED13, before comparing the differences in vascularity and volume. The grafted patient tumor was then divided into subfragments to be kept in freezing media, snap frozen or fixed in formalin and embedded in paraffin. Comparisons in the FFPE samples before and after grafting into the CAM could be made. molecular profiling, while the remaining fragments were kept in freezing media for storage. A pair of sharp forceps is used to grasp the fragments and transfer the fragments to the CAM within minimal PBS attached. Tumor fragments are added onto the CAM near the "Y" bifurcation of a blood vessel. An autoclaved glass rod is used to gently tap on the periderm while ensuring no damage to the CAM, preventing any bleeding or visible rupture of the capillaries. The tumor fragments are then being further settled in with the blunt-end forceps gently pressing onto the CAM. The subfragment is grafted onto the CAM on ED6 and left to grow in size and develop until ED13.

\section{Imaging the CAM Xenograft by Ultrasound Scan}

Ultrasound scans are performed on the Visualsonics Vevo ${ }^{\circledR} 2100$ Imaging System using a $40 \mathrm{MHz}$ center frequency-MS-550D transducer connected to an automated $3 \mathrm{D}$ motorized slider (Fig. 4). The $3 \mathrm{M}^{\mathrm{TM}}$ Tegaderm ${ }^{\mathrm{TM}}$ transparent film dressing is removed and a cling wrap is 


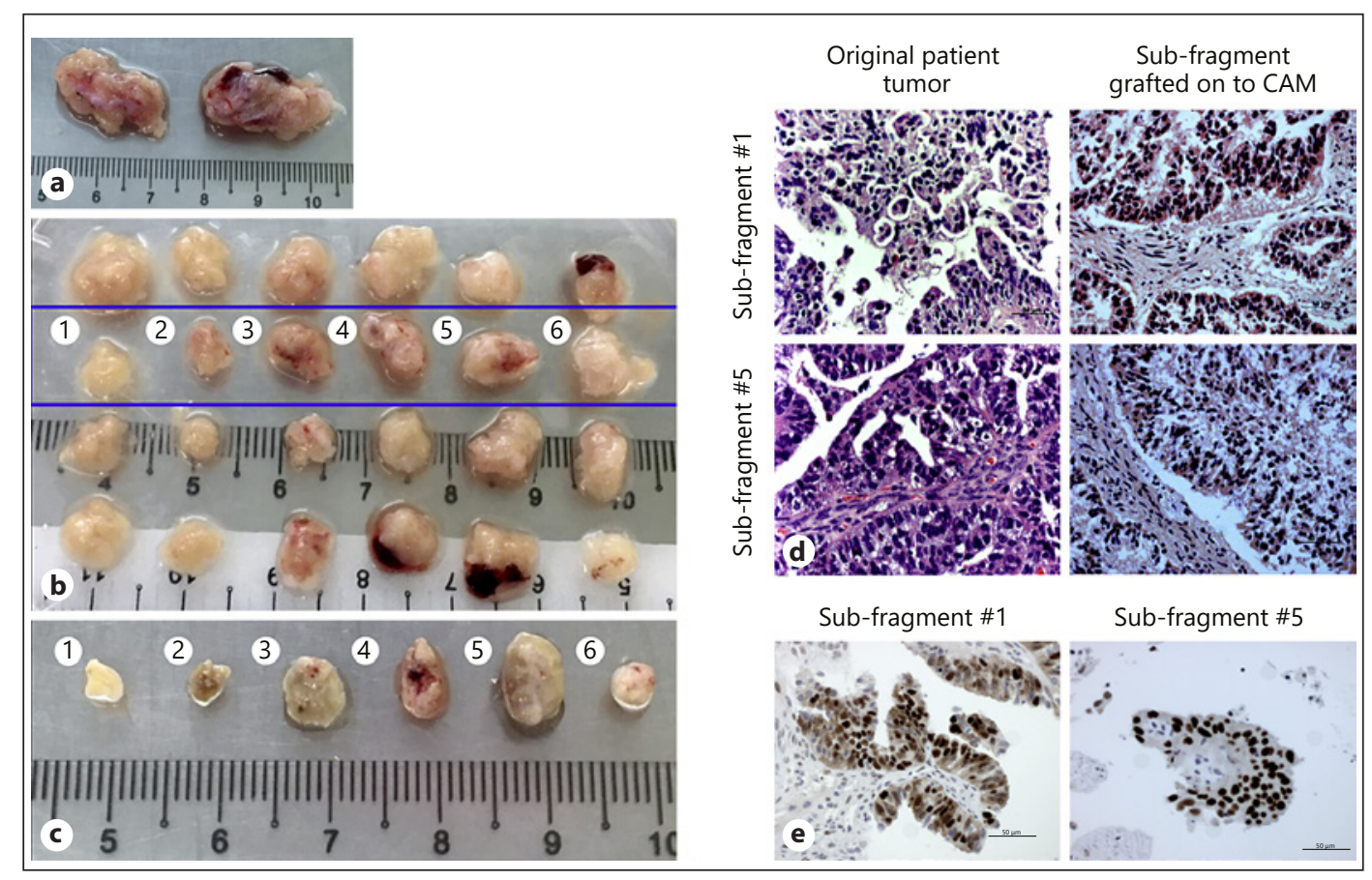

Fig. 3. Engraftment of ovarian cancer patient fragments onto chick CAM. a Original patient tumor sample collected from the operating theater. b Each tumor sample was cut into 12 smaller fragments (as described in Fig. 2). The top row was kept in freezing media for future experiments, second row was grafted onto the CAM on ED6, subfragments of the third row were FFPE-treated and the bottom row was snap frozen in liquid nitrogen. Subfragments 1-6 in the second row were grafted onto the CAM on ED6. c Photograph of harvested tumor subfragments from the CAM on ED13. The subfragments from the original tumors from the blue box (b) were grafted onto the CAM on ED6 and left till ED13 before they were scanned by $3 \mathrm{D}$ ultrasounds and excised from the CAM. The photograph depicts the tumor subfragments excised from the CAM. The tumors harvested were than fixed in $10 \%$ formalin and embedded in paraffin before H\&E staining was performed by the Department of Pathology in National University Hospital of Singapore. d H\&E staining of original ovarian cancer patient fragment 1 (top left) and 5 (bottom left) and subfragment 1 (top right) and 5 (bottom right) after grafting onto CAM for 7 embryonic days. The subfragments post-grafted onto the CAM maintained similar morphology and histology compared to the original ovarian cancer patient fragment. Scale bars, $50 \mu \mathrm{m} . \times 40$. e Immunoexpression of p53 in original patient fragment 5 (left) and subfragment 5 (right) post-grafting onto CAM. The subfragments postgrafted onto the CAM maintained similar immunoexpression of p53 compared to the original ovarian cancer patient fragment. Scale bars, $50 \mu \mathrm{m} . \times 40$. placed over the exposed tumor. A blunt end tweezer is used to gently tap to ensure good contact between the tumor and the cling wrap. Warmed Aquasonic $₫ 100$ Ultrasound transducer gel is placed over the cling wrap and the MS-550D transducer is lowered until contact with the gel is established. Ultrasounds in 3D Power Doppler mode are taken at the multiple cross sections at low 2D gain $(5 \mathrm{~Hz})$ and power Doppler gain $(10 \mathrm{~Hz})$ using the automated 3D motorized slider to be reconstructed into a 3D image. The red areas are indicative of the vasculature within the CAM as well as in the tumor grafted onto the CAM. The cyan lines indicate individual points of measurements across cross sections of the grafted tumor. The bottom left image shows the outline of the grafted tumor situated on the CAM (Fig. 4). All tumor subfragments should remain viable after being grafted onto the CAM for a week.

Several imaging techniques other than ultrasound scanning are applicable as well. Jefferies et al. [2017] applied the bioluminescence imaging on the assessment of tumor cells engineered with luciferase reporter genes. Grafting of cells onto the CAM in combination with either basement membrane extract or gelfoam scaffolds permits a daily noninvasive detection of engineered tumor cells in living chick embryo. Zuo et al. [2015] used the high-resolution MRI [Singh et al., 2001] to monitor tumor growth on the CAM. Herrmann et al. [2018], on the other hand, labeled human neuroblastoma cells with micron-sized particles. The T2-weighted fast low angle shot imaging enables the detection of metastatic deposits in ovo. Although 


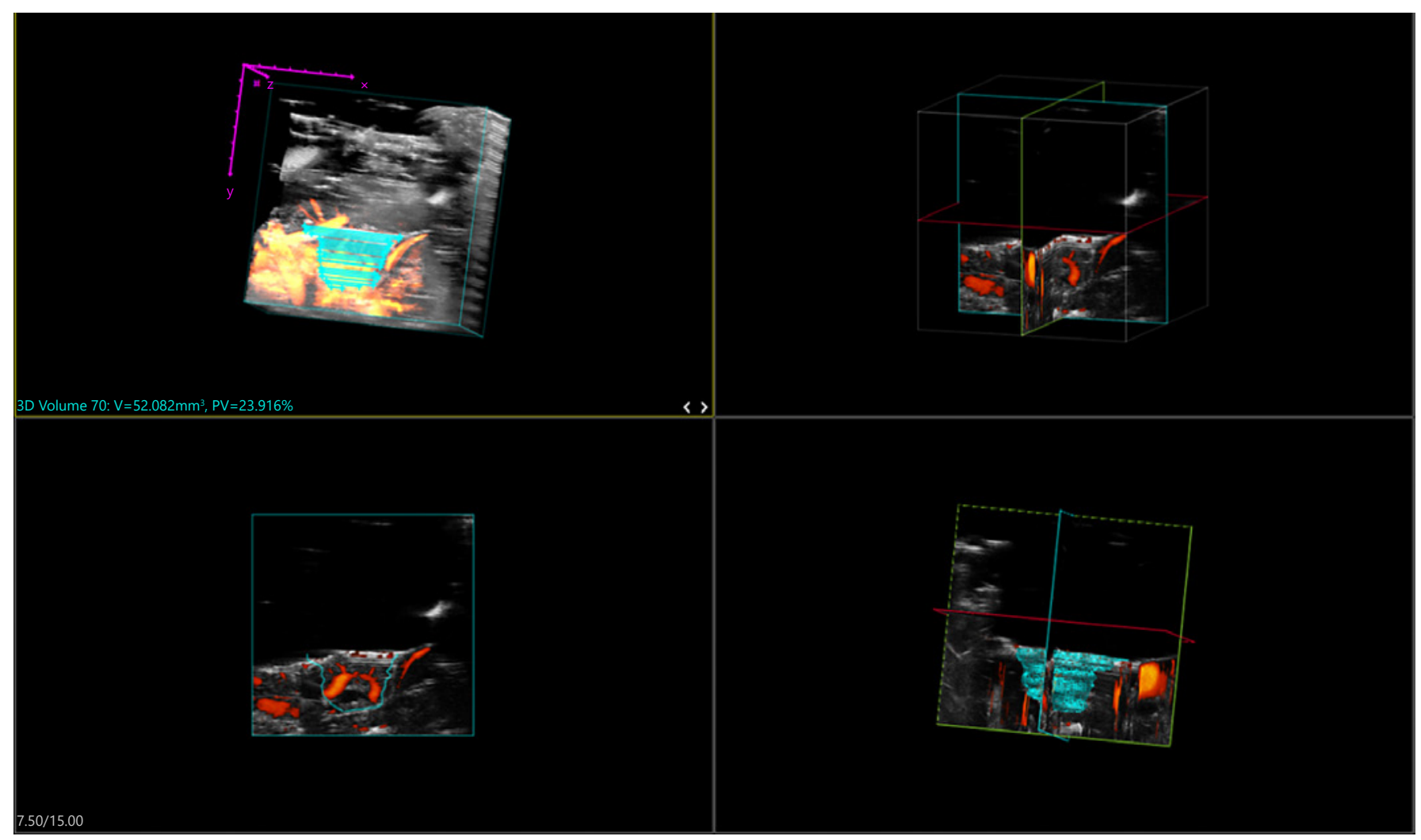

Fig. 4. 3D power Doppler ultrasound. On embryonic day 13, the Tegaderm membrane was removed, and warmed Aquasonic gel was added onto the cling wrap which was carefully placed over the CAM tumors. Using the Visualsonics Vevo 2100 Imaging system, a 550D transducer connected to a 3D Acquisition motor was used to obtain the ultrasound images of the tumors formed or grafted onto the CAM. The figure shows the screenshot of the Vevo Lab 1.7.0 program used to analyze the tumors grafted onto the CAM. Top left: the position of the tumor (in cyan) with the surrounding blood vessels of the CAM (in orange) is shown. The individual cyan lines represent the cross sections which were measured, in order to construct the tumor in a $3 \mathrm{D}$ image. $\mathrm{X}$ and $\mathrm{Y}$ and $\mathrm{Z}$ (in

there are several methods to visualize and quantify the growth or shrinkage of the tumor and tumor vasculature on the CAM, we chose to utilize the 3D doppler mode for the ultrasound imaging as it would be more quantitative as compared to using fluorescence or bioluminescence imaging whereby tumor cells could only be observed in 2D. On the other hand, while high-resolution MRI would provide more accurate measurements to monitor tumor growth, it would likely increase the cost of the experiments significantly. In addition, if time and resources permitted, it would be beneficial to utilize PET-CT scans as well, in order to study about the pharmacokinetics of drugs and molecules as well as tumor progression. purple) represent the axes of the measured area. Top right: the center of axes of the tumor both lengthwise and width-wise is shown. The image could be rotated around to ensure accurate measurement of the grafted tumor. Bottom left: the outline of the grafted tumor in relation to the surrounding vessels of the CAM (in red) is shown. Bottom right: the center of axes as per the top right, together with the individual cross sections (in cyan) and surrounding blood vessels (in red) are shown. After the parallel 2D crosssections obtained were further reconstructed to form $3 \mathrm{D}$ images of the tumors, tumor volumes and percentage vasculatures were calculated using the Vevo Lab 1.7.0 program and indicated on the top left in cyan.

\section{Analysis of the 3D Ultrasound Images}

Image analysis is done using the $3 \mathrm{D}$ analysis software on the Vevo Lab 1.7.0. At least 100 2D sections are obtained and reconstructed into a 3D image wherein tumor volume and percentage vascularization is calculated. The circumference of the tumor is carefully traced for the different sections and the tumor volume as well as the percentage vasculature is calculated at various time points by the software without any damage to the tumors. The cling wrap is simply removed and the window of the CAM is then covered with $3 \mathrm{M}^{\mathrm{TM}}$ Tegader$\mathrm{m}^{\mathrm{TM}}$ transparent film dressing and placed back into the incubator. 
Harvesting and Storage of the PDX Tumors

After the final ultrasound scan is performed latest on ED14, the host chick embryo is then swiftly sacrificed by decapitation, and the CAM with attached tumor is removed by a circular cut using the sharp-pointed scissors, and transferred to a 12-well plate filled with PBS for each individual tumor. Excessive CAM is cut from the graft except for its former attachment site if the tumor is to be re-grafted onto another CAM. The tumors for each condition are then placed on a $10 \mathrm{~cm}$ petri dish and photographed, before cutting into different fragments (Fig. 3c) to be either FFPE-treated, snap frozen in liquid nitrogen or dry ice for future molecular analysis, preserved in freezing media for storage, or to be used for passaging onto the next batch of CAM.

\section{Histopathological Assessment of the CAM PDX}

Histopathological analyses are performed to confirm that the CAM tumor fragments retained the original morphological profile of the patient tumor. The original patient fragments displayed the papillary structures with irregular glandular spaces and darkly stained nuclei which are characteristic of high-grade serous carcinomas. Similarly, the tumor subfragments grafted onto the CAM maintained their morphological features after a week of grafting (Fig. 3d). In addition, both the original patient fragments and CAM tumor subfragments were sent to be analyzed using a p53 stain (DO-7, Dako), which could serve as surrogate marker for TP53 mutations in ovarian carcinoma. Interestingly, the tumor subfragments which were grafted onto the CAM for a week retained the p53 overexpression, as observed by the darkly stained immune-expression of p53 (Fig. 3e).

\section{Conclusion}

The chick CAM is shown to be a robust model for both the inoculation of cell lines and grafting of patient tumors for the future evaluation of drug therapies and the functionality of target genes/pathways in a cost- and time-effective manner. Moreover, the turnover time to test for drug efficacies is only 2 weeks compared to 3-6 months in mice. The CAM model could therefore be used as a quick screening tool before moving onto established mouse models, which require specific expert training in handling mouse models. For instance, we previously identified a unique signaling network downstream of the oncogenic AXL receptor tyrosine kinase pathway in the poor prognosis mesenchymal molecular subtype of OC

Chick CAM Model in Cancer Studies
[Antony et al., 2016; Halmos and Haura, 2016] and utilized the CAM model to show the enhanced efficacy of the AXL inhibitor BGB324 [Holland et al., 2010] in the mesenchymal subtype. The CAM platform was instrumental in the identification of a potential strategy for treating the mesenchymal OC subtype by targeting AXL [Antony and Huang, 2017; Huang RY et al., 2017], and this was subsequently validated in mouse models. Furthermore, we were able to show synergy of therapeutic combinations wherein a tumor suppressor protein OPCML [McKie et al., 2012] that inhibits AXL [Antony et al., 2018] and other RTKs such as EGFR and HER2 [Zanini et al., 2017], further sensitized the mesenchymal subtype to AXL inhibitor BGB324 [Antony et al., 2018; Zurzolo, 2018]. Currently, we are screening additional therapeutics for specific OC subtypes using the CAM model as a first pass and will focus on delineating subtype-specific targets for further preclinical validation in the mouse models.

Furthermore, the ability of the CAM to preserve the histology of the patient tumor fragments that are engrafted can provide additional clinical advantages. For instance, the H\&E staining showed the darkly stained nuclei and papillary spaces with irregular glandular spaces in both the original patient tumor and the tumor subfragment which was engrafted onto the CAM. The TP53 immunohistochemical analysis of the original patient tumor fragment and the grafted subfragment showed p53 overexpression, characteristic of high-grade serous carcinomas. As a next step, in depth molecular analysis such as next-generation sequencing has to be performed in order to determine the actionable mutations of the tumor grafts as well as the drug or combination drug therapies that might be more suitable for these patients. These patients would also be undergoing PET-CT scans at the same time from which we would be able to analyze drug pharmacokinetics by engrafting tumor subfragments onto the CAM and utilizing micro-PET-CT analyses. Given the versatility of the CAM model, it is poised to be a real-time platform for following through the course of treatment of cancer patients and can be used to predict the effectiveness of drugs on the tumor subfragment grafts and evaluation of actionable mutations to develop further targeted therapies.

While the CAM assay is a suitable and highly flexible platform in cancer study, there are still some general limitations that should be taken into consideration during experimental design. Biologically, although the chick embryos are naturally immunodeficient, nonspecific immune responses might still occur during chick immune system development. Also, although being such a useful 
model in the study of metastasis, the short observation period makes it relatively difficult to produce macroscopically visible metastasis to chick tissues or to assess treatment responses. Prolongation of the experimental period could be achieved by re-grafting implanted cells or tissues onto the CAM on another egg. Besides, the different drug metabolism and immune system in chicks as compared with mammals might lead to distinct responses while accepting treatments. Therefore, the CAM assay might be useful in drug screening; nevertheless, mammalian models will still be necessary to be tested during preclinical studies once potential drugs have been discovered from the chick CAM assay.

\section{Conflict of Interest Statement}

The authors have no conflicts of interest to declare.

\section{Funding Sources}

This work was supported by the Yushan Scholar Program by the Ministry of Education, Taiwan (NTU-109V0402) and NTU Core Consortiums (NTUCC-109L893001) to R.Y.-J.H.

\section{Author Contributions}

Conceptualization, R.Y.-J.H.; Writing, P.-Y.C., A.P.-F.K., J.A., and R.Y.-J.H.; Case study, A.P.-F.K., J.A., R.Y.-J.H. All authors have read and agreed to the published version of the manuscript.

\section{References}

Aguirre-Ghiso JA, Liu D, Mignatti A, Kovalski K, Ossowski L. Urokinase receptor and fibronectin regulate the ERK(MAPK) to p38(MAPK) activity ratios that determine carcinoma cell proliferation or dormancy in vivo. Mol Biol Cell. 2001;12(4):863-79.

Aguirre-Ghiso JA, Estrada Y, Liu D, Ossowski L. ERK(MAPK) activity as a determinant of tumor growth and dormancy; regulation by p38(SAPK). Cancer Res. 2003;63(7):1684-95.

Aguirre-Ghiso JA, Ossowski L, Rosenbaum SK. Green fluorescent protein tagging of extracellular signal-regulated kinase and p38 pathways reveals novel dynamics of pathway activation during primary and metastatic growth. Cancer Res. 2004;64(20):7336-45.

Ames JJ, Henderson T, Liaw L, Brooks PC. Methods for Analyzing Tumor Angiogenesis in the Chick Chorioallantoic Membrane Model. Methods Mol Biol. 2016;1406:255-69.

Antony J, Huang RY. AXL-Driven EMT State as a Targetable Conduit in Cancer. Cancer Res. 2017;77(14):3725-32.

Antony J, Tan TZ, Kelly Z, Low J, Choolani M, Recchi C, et al. The GAS6-AXL signaling network is a mesenchymal (Mes) molecular subtype-specific therapeutic target for ovarian cancer. Sci Signal. 2016;9(448):ra97.

Antony J, Zanini E, Kelly Z, Tan TZ, Karali E, Alomary $\mathrm{M}$, et al. The tumour suppressor OPCML promotes AXL inactivation by the phosphatase PTPRG in ovarian cancer. EMBO Rep. 2018;19(8):e45670.

Ausprunk DH, Folkman J. Vascular injury in transplanted tissues. Fine structural changes in tumor, adult, and embryonic blood vessels. Virchows Arch B Cell Pathol. 1976(1):31-44.

Ausprunk DH, Knighton DR, Folkman J. Vascularization of normal and neoplastic tissues grafted to the chick chorioallantois. Role of host and preexisting graft blood vessels. Am J Pathol. 1975;79(3):597-618
Balciuniene N, Tamasauskas A, Valanciute A, Deltuva V, Vaitiekaitis G, Gudinaviciene I, et al. Histology of human glioblastoma transplanted on chicken chorioallantoic membrane. Medicina (Kaunas). 2009;45(2):12331.

Balke M, Neumann A, Szuhai K, Agelopoulos K, August C, Gosheger G, et al. A short-term in vivo model for giant cell tumor of bone. BMC Cancer. 2011;11:241.

Barrie R, Woltering EA, Hajarizadeh H, Mueller $\mathrm{C}$, Ure T, Fletcher WS. Inhibition of angiogenesis by somatostatin and somatostatinlike compounds is structurally dependent. J Surg Res. 1993;55(4):446-50.

Bertossi M, Virgintino D, Coltey P, Errede M, Mancini L, Roncali L. Angiogenesis and endothelium phenotype expression in embryonic adrenal gland and cerebellum grafted onto chorioallantoic membrane. Angiogenesis. 1999;3(4):305-15.

Cancer Genome Atlas Research Network. Integrated genomic analyses of ovarian carcinoma. Nature. 2011;474(7353):609-15.

Chambers AF, Shafir R, Ling V. A model system for studying metastasis using the embryonic chick. Cancer Res. 1982;42(10):4018-25.

Cimpean AM, Ribatti D, Raica M. The chick embryo chorioallantoic membrane as a model to study tumor metastasis. Angiogenesis. 2008; 11(4):311-9.

Cuadros MA, Coltey P, Carmen Nieto M, Martin C. Demonstration of a phagocytic cell system belonging to the hemopoietic lineage and originating from the yolk sac in the early avian embryo. Development. 1992;115(1):157-68.

Dagg CP, Karnofsky DA, Roddy J. Growth of transplantable human tumors in the chick embryo and hatched chick. Cancer Res. 1956; 16(7):589-94

Dagogo-Jack I, Shaw AT. Tumour heterogeneity and resistance to cancer therapies. Nat Rev Clin Oncol. 2018;15(2):81-94.
Davison TF. The immunologists' debt to the chicken. Br Poult Sci. 2003;44(1):6-21.

DeBord LC, Pathak RR, Villaneuva M, Liu HC, Harrington DA, Yu W, et al. The chick chorioallantoic membrane (CAM) as a versatile patient-derived xenograft (PDX) platform for precision medicine and preclinical research. Am J Cancer Res. 2018;8(8):1642-60.

DeFouw DO, Rizzo VJ, Steinfeld R, Feinberg RN Mapping of the microcirculation in the chick chorioallantoic membrane during normal angiogenesis. Microvasc Res. 1989;38(2):13647.

DeRose YS, Wang G, Lin YC, Bernard PS, Buys SS, Ebbert MT, et al. Tumor grafts derived from women with breast cancer authentically reflect tumor pathology, growth, metastasis and disease outcomes. Nat Med. 2011;17(11): 1514-20.

Deryugina EI. Chorioallantoic Membrane Microtumor Model to Study the Mechanisms of Tumor Angiogenesis, Vascular Permeability, and Tumor Cell Intravasation. Methods $\mathrm{Mo}$ Biol. 2016;1430:283-98.

Deryugina EI, Quigley JP. Chick embryo chorioallantoic membrane model systems to study and visualize human tumor cell metastasis. Histochem Cell Biol. 2008;130(6):1119-30.

Deryugina EI, Zijlstra A, Partridge JJ, Kupriyanova TA, Madsen MA, Papagiannakopoulos T, et al. Unexpected effect of matrix metalloproteinase down-regulation on vascular intravasation and metastasis of human fibrosarcoma cells selected in vivo for high rates of dissemination. Cancer Res. 2005;65(23):10959-69.

Dimitropoulou C, Malkusch W, Fait E, Maragoudakis ME, Konerding MA. The vascular architecture of the chick chorioallantoic membrane: sequential quantitative evaluation using corrosion casting. Angiogenesis. 1998; 2(3):255-63. 
Dimova I, Karthik S, Makanya A, Hlushchuk R, Semela D, Volarevic V, et al. SDF-1/CXCR4 signalling is involved in blood vessel growth and remodelling by intussusception. J Cell Mol Med. 2019;23(6):3916-26.

Doukas CN, Maglogiannis I, Chatziioannou A, Papapetropoulos A. Automated angiogenesis quantification through advanced image processing techniques. Conf Proc IEEE Eng Med Biol Soc. 2006; 1:2345-8.

Dünker N, Jendrossek V. Implementation of the Chick Chorioallantoic Membrane (CAM) Model in Radiation Biology and Experimental Radiation Oncology Research. Cancers (Basel). 2019;11(10):1499.

Durupt F, Koppers-Lalic D, Balme B, Budel L, Terrier O, Lina B, et al. The chicken chorioallantoic membrane tumor assay as model for qualitative testing of oncolytic adenoviruses. Cancer Gene Ther. 2012;19(1):58-68.

Fergelot P, Bernhard JC, Soulet F, Kilarski WW Léon C, Courtois $\mathrm{N}$, et al. The experimental renal cell carcinoma model in the chick embryo. Angiogenesis. 2013;16(1):181-94.

Ferician O, Cimpean AM, Avram S, Raica M. Endostatin Effects on Tumor Cells and Vascular Network of Human Renal Cell Carcinoma Implanted on Chick Embryo Chorioallantoic Membrane. Anticancer Res. 2015; 35(12):6521-8.

Fiebig HH, Maier A, Burger AM. Clonogenic assay with established human tumour xenografts: correlation of in vitro to in vivo activity as a basis for anticancer drug discovery. Eur J Cancer. 2004;40(6):802-20.

Folkman J. Tumor angiogenesis: therapeutic implications. N Engl J Med. 1971;285(21):1182-

Form DM, Auerbach R. PGE2 and angiogenesis. Proc Soc Exp Biol Med. 1983;172(2):214-8.

Ghaffari-Tabrizi-Wizsy N, Passegger CA, Nebel L, Krismer F, Herzer-Schneidhofer G, Schwach G, et al. The avian chorioallantoic membrane as an alternative tool to study medullary thyroid cancer. Endocr Connect. 2019;8(5):462-7.

Gronau S, Thess B, Riechelmann H, Fischer Y, Schmitt A, Schmitt M. An autologous system for culturing head and neck squamous cell carcinomas for the assessment of cellular therapies on the chorioallantois membrane. Eur Arch Otorhinolaryngol. 2006;263(4): $308-12$.

Halmos B, Haura EB. New twists in the AXL(e) of tumor progression. Sci Signal. 2016;9(448): fs 14 .

Hanahan D, Weinberg RA. Hallmarks of cancer: the next generation. Cell. 2011;144(5):64674.

Herrmann A, Taylor A, Murray P, Poptani H, Sée V. Magnetic Resonance Imaging for Characterization of a Chick Embryo Model of Cancer Cell Metastases. Mol Imaging. 2018;17: 1536012118809585 .
Hincke MT, Da Silva M, Guyot N, Gautron J McKee MD, Guabiraba-Brito R, et al. Dynamics of Structural Barriers and Innate Immune Components during Incubation of the Avian Egg: Critical Interplay between Autonomous Embryonic Development and Maternal Anticipation. J Innate Immun. 2019; 11(2):111-24.

Ho BY, Wu YM, Hsu YW, Hsu LC, Kuo YH, Chang KJ, et al. Effects of Monascus-fermented rice extract on malignant cell-associated neovascularization and intravasation determined using the chicken embryo chorioallantoic membrane model. Integr Cancer Ther. 2010;9(2):204-12.

Holland SJ, Pan A, Franci C, Hu Y, Chang B, Li $\mathrm{W}$, et al. R428, a selective small molecule inhibitor of Axl kinase, blocks tumor spread and prolongs survival in models of metastatic breast cancer. Cancer Res. 2010;70(4):154454.

Houssaint E. Cell lineage segregation during bursa of Fabricius ontogeny. J Immunol. 1987; 138(11):3626-34.

Houssaint E, Tobin S, Cihak J, Lösch U. A chicken leukocyte common antigen: biochemical characterization and ontogenetic study. Eur J Immunol. 1987;17(2):287-90.

Huang RY, Antony J, Tan TZ, Tan DS. Targeting the AXL signaling pathway in ovarian cancer. Mol Cell Oncol. 2017;4(2):e1263716.

Huang WT, Cen WL, He RQ, Xie Y, Zhang Y, Li $\mathrm{P}$, et al. Effect of miR146a5p on tumor growth in NSCLC using chick chorioallantoic membrane assay and bioinformatics investigation. Mol Med Rep. 2017;16(6):8781-92.

Ismail MS, Torsten U, Dressler C, Diederichs JE, Hüske $S$, Weitzel $\mathrm{H}$, et al. Photodynamic Therapy of Malignant Ovarian Tumours Cultivated on CAM. Lasers Med Sci. 1999;14(2): 91-6.

Jankovic BD, Isakovic K, Lukic ML, Vujanovic NL, Petrovic S, Markovic BM. Immunological capacity of the chicken embryo. I. Relationship between the maturation of lymphoid tissues and the occurrence of cell-mediated immunity in the developing chicken embryo Immunology. 1975;29(3):497-508.

Janse EM, Jeurissen SH. Ontogeny and function of two non-lymphoid cell populations in the chicken embryo. Immunobiology. 1991; 182(5):472-81.

Jefferies B, Lenze F, Sathe A, Truong N, Anton M, von Eisenhart-Rothe R, et al. Non-invasive imaging of engineered human tumors in the living chicken embryo. Sci Rep. 2017;7(1): 4991.

Jung J, Seol HS, Chang S. The Generation and Application of Patient-Derived Xenograft Model for Cancer Research. Cancer Res Treat. 2018; 50(1):1-10.

Kannaki TR, Reddy MR, Verma PC, Shanmugam M. Differential Toll-like receptor (TLR) mRNA expression patterns during chicken embryological development. Anim Biotechnol. 2015;26(2):130-5.
Karnofsky DA, Ridgway LP, Patterson PA. Tumor transplantation to the chick embryo. Ann N Y Acad Sci. 1952;55(2):313-29.

Kaufman N, Kinney TD, Mason EJ, Prieto LC Jr. Maintenance of human neoplasm on the chick chorioallantoic membrane. Am J Pathol. 1956;32(2):271-85.

Kim J, Yu W, Kovalski K, Ossowski L. Requirement for specific proteases in cancer cell intravasation as revealed by a novel semiquantitative PCR-based assay. Cell. 1998;94(3): 353-62.

Kirchner LM, Schmidt SP, Gruber BS. Quantitation of angiogenesis in the chick chorioallantoic membrane model using fractal analysis. Microvasc Res. 1996;51(1):2-14.

Kisker O, Onizuka S, Banyard J, Komiyama T, Becker CM, Achilles EG, et al. Generation of multiple angiogenesis inhibitors by human pancreatic cancer. Cancer Res. 2001;61(19): 7298-304.

Klagsbrun M, Knighton D, Folkman J. Tumor angiogenesis activity in cells grown in tissue culture. Cancer Res. 1976;36(1):110-4.

Klingenberg M, Becker J, Eberth S, Kube D, Wilting J. The NADPH oxidase inhibitor imipramine-blue in the treatment of Burkitt lymphoma. Mol Cancer Ther. 2014;13(4):833-41.

Knighton D, Ausprunk D, Tapper D, Folkman J. Avascular and vascular phases of tumour growth in the chick embryo. Br J Cancer. 1977;35(3):347-56.

Komatsu A, Matsumoto K, Saito T, Muto M, Tamanoi F. Patient Derived Chicken Egg Tumor Model (PDcE Model): Current Status and Critical Issues. Cells. 2019;8(5):440.

Korngold L, Lipari R. Tissue antigens of human tumors grown in rats, hamsters, and eggs. Cancer Res. 1955;15(3):159-61.

Landree LE, Hanlon AL, Strong DW, Rumbaugh G, Miller IM, Thupari JN, et al. C75, a fatty acid synthase inhibitor, modulates AMP-activated protein kinase to alter neuronal energy metabolism. J Biol Chem. 2004;279(5):381727.

Leong HS, Chambers AF, Lewis JD. Assessing cancer cell migration and metastatic growth in vivo in the chick embryo using fluorescence intravital imaging. Methods Mol Biol. 2012;872:1-14

Li M, Pathak RR, Lopez-Rivera E, Friedman SL, Aguirre-Ghiso JA, Sikora AG. The In Ovo Chick Chorioallantoic Membrane (CAM) Assay as an Efficient Xenograft Model of $\mathrm{He}$ patocellular Carcinoma. J Vis Exp. 2015;104: 52411.

Lokman NA, Elder AS, Ricciardelli C, Oehler MK. Chick chorioallantoic membrane (CAM) assay as an in vivo model to study the effect of newly identified molecules on ovarian cancer invasion and metastasis. Int J Mol Sci. 2012; 13(8):9959-70 
Lugassy C, Torres-Muñoz JE, Kleinman HK, Ghanem G, Vernon S, Barnhill RL. Overexpression of malignancy-associated laminins and laminin receptors by angiotropic human melanoma cells in a chick chorioallantoic membrane model. J Cutan Pathol. 2009;36(12): 1237-43.

Mangieri D, Nico B, Benagiano V, De Giorgis M, Vacca A, Ribatti D. Angiogenic activity of multiple myeloma endothelial cells in vivo in the chick embryo chorioallantoic membrane assay is associated to a down-regulation in the expression of endogenous endostatin. J Cell Mol Med. 2008;12(3):1023-8.

Marimpietri D, Nico B, Vacca A, Mangieri D, Catarsi P, Ponzoni M, et al. Synergistic inhibition of human neuroblastoma-related angiogenesis by vinblastine and rapamycin. Oncogene. 2005;24(45):6785-95.

Marzullo A, Vacca A, Roncali L, Pollice L, Ribatti D. Angiogenesis in hepatocellular carcinoma: an experimental study in the chick embryo chorioallantoic membrane. Int J Oncol. 1998; 13(1):17-21.

Massagué J, Obenauf AC. Metastatic colonization by circulating tumour cells. Nature. 2016; 529(7586):298-306.

Masters JR. Human cancer cell lines: fact and fantasy. Nat Rev Mol Cell Biol. 2000;1(3):233-6.

McKie AB, Vaughan S, Zanini E, Okon IS, Louis L, de Sousa C, et al. The OPCML tumor suppressor functions as a cell surface repressoradaptor, negatively regulating receptor tyrosine kinases in epithelial ovarian cancer. Cancer Discov. 2012;2(2):156-71.

Meade KG, Higgs R, Lloyd AT, Giles S, O'Farrelly C. Differential antimicrobial peptide gene expression patterns during early chicken embryological development. Dev Comp Immunol. 2009;33(4):516-24.

Mostafa LK, Jones DB, Wright DH. Mechanism of the induction of angiogenesis by human neoplastic lymphoid tissue: studies on the chorioallantoic membrane (CAM) of the chick embryo. J Pathol. 1980;132(3):191-205.

Nowak-Sliwinska P, Ballini JP, Wagnières G, van den Bergh $\mathrm{H}$. Processing of fluorescence angiograms for the quantification of vascular effects induced by anti-angiogenic agents in the CAM model. Microvasc Res. 2010;79(1):218.

Oh SH, Kim WY, Lee OH, Kang JH, Woo JK, Kim $\mathrm{JH}$, et al. Insulin-like growth factor binding protein-3 suppresses vascular endothelial growth factor expression and tumor angiogenesis in head and neck squamous cell carcinoma. Cancer Sci. 2012;103(7):1259-66.

Ossowski L, Aguirre Ghiso J, Liu D, Yu W, Kovalski $\mathrm{K}$. The role of plasminogen activator receptor in cancer invasion and dormancy. Medicina (B Aires). 1999;59(5 Pt 2):547-52.

Petruzzelli GJ, Snyderman CH, Johnson JT, Myers EN. Angiogenesis induced by head and neck squamous cell carcinoma xenografts in the chick embryo chorioallantoic membrane model. Ann Otol Rhinol Laryngol. 1993; 102(3 Pt 1):215-21.
Pyriochou A, Tsigkos S, Vassilakopoulos T, Cottin T, Zhou Z, Gourzoulidou E, et al. Antiangiogenic properties of a sulindac analogue. Br J Pharmacol. 2007;152(8):1207-14.

Qureshi MA, Heggen CL, Hussain I. Avian macrophage: effector functions in health and disease. Dev Comp Immunol. 2000;24(2区3): 103-19.

Ratcliffe M, Härtle S. B Cells, the bursa of Fabricius and the generation of antibody repertoires. In: Schat KA, Kaspers B, Kaiser P, editors. Avian Immunology. Elsevier; 2014. p. 65-89.

Ribatti D. Judah Folkman, a pioneer in the study of angiogenesis. Angiogenesis. 2008;11(1):310.

Ribatti D. The chick embryo chorioallantoic membrane as a model for tumor biology. Exp Cell Res. 2014;328(2):314-24.

Ribatti D. The chick embryo chorioallantoic membrane (CAM). A multifaceted experimental model. Mech Dev. 2016;141:70-7.

Ribatti D, Tamma R. The chick embryo chorioallantoic membrane as an in vivo experimental model to study multiple myeloma. Enzymes. 2019;46:23-35.

Ribatti D, Vacca A, Roncali L, Dammacco F. The chick embryo chorioallantoic membrane as a model for in vivo research on angiogenesis. Int J Dev Biol. 1996;40(6):1189-97.

Ribatti D, Alessandri G, Baronio M, Raffaghello L, Cosimo E, Marimpietri D, et al. Inhibition of neuroblastoma-induced angiogenesis by fenretinide. Int J Cancer. 2001a;94(3):31421.

Ribatti D, Nico B, Vacca A, Roncali L, Burri PH, Djonov V. Chorioallantoic membrane capillary bed: a useful target for studying angiogenesis and anti-angiogenesis in vivo. Anat Rec. 2001b;264(4):317-24.

Ribatti D, Nico B, Vacca A, Presta M. The gelatin sponge-chorioallantoic membrane assay. Nat Protoc. 2006;1(1):85-91.

Rovithi M, Avan A, Funel N, Leon LG, Gomez VE, Wurdinger T, et al. Development of bioluminescent chick chorioallantoic membrane (CAM) models for primary pancreatic cancer cells: a platform for drug testing. Sci Rep. 2017;7:44686

Rudy SF, Brenner JC, Harris JL, Liu J, Che J, Scott $\mathrm{MV}$, et al. In vivo Wnt pathway inhibition of human squamous cell carcinoma growth and metastasis in the chick chorioallantoic model. J Otolaryngol Head Neck Surg. 2016;45:26.

Sachs N, Clevers H. Organoid cultures for the analysis of cancer phenotypes. Curr Opin Genet Dev. 2014;24:68-73.

Schilling MA, Katani R, Memari S, Cavanaugh M, Buza J, Radzio-Basu J, et al. Transcriptional Innate Immune Response of the Developing Chicken Embryo to Newcastle Disease Virus Infection. Front Genet. 2018;9:61.

Schlatter P, König MF, Karlsson LM, Burri PH. Quantitative study of intussusceptive capillary growth in the chorioallantoic membrane (CAM) of the chicken embryo. Microvasc Res. 1997;54(1):65-73.
Schneider T, Osl F, Friess T, Stockinger H, Scheuer WV. Quantification of human Alu sequences by real-time PCR--an improved method to measure therapeutic efficacy of anti-metastatic drugs in human xenotransplants. Clin Exp Metastasis. 2002;19(7):57182.

Seidlitz E, Korbie D, Marien L, Richardson M, Singh G. Quantification of anti-angiogenesis using the capillaries of the chick chorioallantoic membrane demonstrates that the effect of human angiostatin is age-dependent. Microvasc Res. 2004;67(2):105-16.

Shing Y, Folkman J, Sullivan R, Butterfield C, Murray J, Klagsbrun M. Heparin affinity: purification of a tumor-derived capillary endothelial cell growth factor. Science. 1984; 223(4642):1296-9.

Shioda T, Munn LL, Fenner MH, Jain RK, Isselbacher KJ. Early events of metastasis in the microcirculation involve changes in gene expression of cancer cells. Tracking mRNA levels of metastasizing cancer cells in the chick embryo chorioallantoic membrane. Am J Pathol. 1997;150(6):2099-112.

Shoin K, Yamashita J, Enkaku F, Sasaki T, Tanaka M, Endo Y. Chick embryo assay as chemosensitivity test for malignant glioma. Jpn J Cancer Res. 1991;82(10):1165-70.

Singh SN, Vats P, Shyam R, Suri S, Kumria MM, Ranganathan S, et al. Role of neuropeptide $\mathrm{Y}$ and galanin in high altitude induced anorexia in rats. Nutr Neurosci. 2001;4(4):323-31.

Skowron MA, Sathe A, Romano A, Hoffmann MJ, Schulz WA, van Koeveringe GA, et al. Applying the chicken embryo chorioallantoic membrane assay to study treatment approaches in urothelial carcinoma. Urol Oncol. 2017; 35(9):544-e23.

Sommers SC, Sullivan BA, Warren S. Heterotransplantation of human cancer. III. Chorioallantoic membranes of embryonated eggs. Cancer Res. 1952;12(12):915-7.

Steiner R. Angiostatic activity of anticancer agents in the chick embryo chorioallantoic membrane (CHE-CAM) assay. EXS. 1992;61: 449-54.

Strick DM, Waycaster RL, Montani JP, Gay WJ, Adair TH. Morphometric measurements of chorioallantoic membrane vascularity: effects of hypoxia and hyperoxia. Am J Physiol. 1991; 260(4 Pt 2):H1385-9.

Strojnik T, Kavalar R, Barone TA, Plunkett RJ. Experimental model and immunohistochemical comparison of U87 human glioblastoma cell xenografts on the chicken chorioallantoic membrane and in rat brains. Anticancer Res. 2010;30(12):4851-60.

Subauste MC, Kupriyanova TA, Conn EM, Ardi VC, Quigley JP, Deryugina EI. Evaluation of metastatic and angiogenic potentials of human colon carcinoma cells in chick embryo model systems. Clin Exp Metastasis. 2009; 26(8):1033-47. 
Sudha T, Yalcin M, Lin HY, Elmetwally AM, Nazeer T, Arumugam T, et al. Suppression of pancreatic cancer by sulfated non-anticoagulant low molecular weight heparin. Cancer Lett. 2014;350(1区2):25-33.

Swadi R, Mather G, Pizer BL, Losty PD, See V, Moss D. Optimising the chick chorioallantoic membrane xenograft model of neuroblastoma for drug delivery. BMC Cancer. 2018; 18(1):28.

Sys G, Van Bockstal M, Forsyth R, Balke M, Poffyn $B$, Uyttendaele $D$, et al. Tumor grafts derived from sarcoma patients retain tumor morphology, viability, and invasion potential and indicate disease outcomes in the chick chorioallantoic membrane model. Cancer Lett. 2012;326(1):69-78.

Taizi M, Deutsch VR, Leitner A, Ohana A, Goldstein RS. A novel and rapid in vivo system for testing therapeutics on human leukemias. Exp Hematol. 2006;34(12):1698-708.

Tan TZ, Miow QH, Huang RY, Wong MK, Ye J, Lau JA, et al. Functional genomics identifies five distinct molecular subtypes with clinical relevance and pathways for growth control in epithelial ovarian cancer. EMBO Mol Med. 2013;5(7):1051-66.

Tay SL, Heng PW, Chan LW. The chick chorioallantoic membrane imaging method as a platform to evaluate vasoactivity and assess irritancy of compounds. J Pharm Pharmacol. 2012;64(8):1128-37.

Tentler JJ, Tan AC, Weekes CD, Jimeno A, Leong S, Pitts TM, et al. Patient-derived tumour xenografts as models for oncology drug development. Nat Rev Clin Oncol. 2012;9(6):33850.

Tothill RW, Tinker AV, George J, Brown R, Fox $\mathrm{SB}$, Lade S, et al. Novel molecular subtypes of serous and endometrioid ovarian cancer linked to clinical outcome. Clin Cancer Res. 2008;14(16):5198-208.

Tufan AC, Satiroglu-Tufan NL. The chick embryo chorioallantoic membrane as a model system for the study of tumor angiogenesis invasion and development of anti-angiogenic agents. Curr Cancer Drug Targets. 2005;5(4): $249-66$.

Uloza V, Kuzminienė A, Šalomskaitè-Davalgienė S, Palubinskienè J, Balnytè I, Ulozienè I, et al.
Effect of Laryngeal Squamous Cell Carcinoma Tissue Implantation on the Chick Embryo Chorioallantoic Membrane: Morphometric Measurements and Vascularity. Biomed Res Int. 2015;2015:629754.

Uloza V, Kuzminienè A, Palubinskienè J, Balnytè I, Ulozienė I, Valančiūtè A. Model of human recurrent respiratory papilloma on chicken embryo chorioallantoic membrane for tumor angiogenesis research. Histol Histopathol. 2017;32(7):699-710.

Valdes TI, Kreutzer D, Moussy F. The chick chorioallantoic membrane as a novel in vivo model for the testing of biomaterials. J Biomed Mater Res. 2002;62(2):273-82.

Veinotte CJ, Dellaire G, Berman JN. Hooking the big one: the potential of zebrafish xenotransplantation to reform cancer drug screening in the genomic era. Dis Model Mech. 2014;7(7):745-54.

Vickerman MB, Keith PA, McKay TL, Gedeon DJ, Watanabe M, Montano M, et al. VESGEN 2D: automated, user-interactive software for quantification and mapping of angiogenic and lymphangiogenic trees and networks. Anat Rec (Hoboken). 2009;292(3):320-32.

Vu BT, Shahin SA, Croissant J, Fatieiev Y, Matsumoto K, Le-Hoang Doan T, et al. Chick chorioallantoic membrane assay as an in vivo model to study the effect of nanoparticlebased anticancer drugs in ovarian cancer. Sci Rep. 2018;8(1):8524.

Walewska M, Dolka I, Małek A, Wojtalewicz A, Wojtkowska A, Żbikowski A, et al. Experimental tumor growth of canine osteosarcoma cell line on chick embryo chorioallantoic membrane (in vivo studies). Acta Vet Scand. 2017;59(1):30.

Xiao X, Zhou X, Ming H, Zhang J, Huang G, Zhang Z, et al. Chick Chorioallantoic Membrane Assay: A 3D Animal Model for Study of Human Nasopharyngeal Carcinoma. PLoS One. 2015;10(6): $\mathrm{e} 0130935$.

Xu C, Li X, Liu P, Li M, Luo F. Patient-derived xenograft mouse models: A high fidelity tool for individualized medicine. Oncol Lett. 2019; 17(1):3-10.

Zabielska-Koczywas K, Dolka I, Krol M, Zbikowski A, Lewandowski W, Mieczkowski J, et al. Doxorubicin Conjugated to Glutathione Stabilized Gold Nanoparticles (Au-GSH-Dox) as an Effective Therapeutic Agent for Feline Injection-Site Sarcomas-Chick Embryo Chorioallantoic Membrane Study. Molecules. 2017; 22(2):253.

Zanini E, Louis LS, Antony J, Karali E, Okon IS, McKie AB, et al. The Tumor-Suppressor Protein OPCML Potentiates Anti-EGFR- and Anti-HER2-Targeted Therapy in HER2-Positive Ovarian and Breast Cancer. Mol Cancer Ther. 2017;16(10):2246-56.

Zatterstrom UK, Braakhuis BJ, Wennerberg J, van Dongen GA, Attewell R, Nauta JJ, et al Growth of xenografted squamous cell carcinoma of the head and neck--possible correlation with patient survival. APMIS. 1992; 100(11):976-80.

Zhao Z, Bauer N, Aleksandrowicz E, Yin L, Gladkich J, Gross W, et al. Intraductal papillary mucinous neoplasm of the pancreas rapidly xenografts in chicken eggs and predicts aggressiveness. Int J Cancer. 2018;142(7):144052.

Zhou Q, Qi CL, Li Y, He XD, Li JC, Zhang QQ, et al. A novel four-step system for screening angiogenesis inhibitors. Mol Med Rep. 2013; 8(6): 1734-40.

Zijlstra A, Mellor R, Panzarella G, Aimes RT, Hooper JD, Marchenko ND, et al. A quantitative analysis of rate-limiting steps in the metastatic cascade using human-specific realtime polymerase chain reaction. Cancer Res. 2002;62(23):7083-92.

Zijlstra A, Seandel M, Kupriyanova TA, Partridge JJ, Madsen MA, Hahn-Dantona EA, et al. Proangiogenic role of neutrophil-like inflammatory heterophils during neovascularization induced by growth factors and human tumor cells. Blood. 2006;107(1):317-27.

Zuo Z, Syrovets T, Genze F, Abaei A, Ma G, Simmet $\mathrm{T}$, et al. High-resolution MRI analysis of breast cancer xenograft on the chick chorioallantoic membrane. NMR Biomed. 2015; 28(4):440-7.

Zuo Z, Syrovets T, Wu Y, Hafner S, Vernikouskaya I, Liu W, et al. The CAM cancer xenograft as a model for initial evaluation of $\mathrm{MR}$ labelled compounds. Sci Rep. 2017;7:46690.

Zurzolo C. Synergistic inactivation of AXL: a (cross)road to cure ovarian cancer?. EMBO Rep. 2018;19(8):e46492. 